\title{
FACILITY MANAGEMENT USING DIGITAL OBEYA ROOM BY INTEGRATING BIM-LEAN APPROACHES - AN EMPIRICAL STUDY
}

\author{
Daniel Luiz de Mattos NASCIMENTO ${ }^{1,2}{ }^{*}$, Osvaldo Luiz Gonçalves QUELHAS ${ }^{1}$, \\ Marcelo Jasmim MEIRIÑO ${ }^{1}$, Rodrigo Goyannes Gusmão CAIADO ${ }^{1,2}$, \\ Simone D. J. BARBOSA ${ }^{3}$, Paulo IVSON ${ }^{2,3}$ \\ ${ }^{1}$ Department of Sustainable Management Systems, Federal Fluminense University, Niteroi, Brazil \\ ${ }^{2}$ Tecgraf Institute, PUC-Rio, Rio de Janeiro, Brazil \\ ${ }^{3}$ Department of Informatics, PUC-Rio, Rio de Janeiro, Brazil
}

Received 28 May 2018; accepted 22 June 2018

\begin{abstract}
This paper applies a methodology for interdisciplinary Facilities Management (FM) by alingment between Building Information Modeling (BIM) and Lean. Initially, the literature review of BIM, FM and Lean principles. Afterwards, the research applies the Digital Obeya Room for improved FM and describes its application on a real-world case study. Lastly, the work presents a survey with specialists to assess the relevance of each BIM-Lean concepts and correlate their perceptions with the empirical results. The main collaborations of this work are: a conceptual framework that relates the PDCA (Plan-Do-Check-Act) cycle with BIM-Lean approaches; the identification of the most relevant BIM functionalies and Lean principles; and the real-world application of the framework procedures on FM.
\end{abstract}

Keywords: Building Information Modeling, facility management, interdisciplinary management, Lean Thinking, Plan-DoCheck-Act.

\section{Notations}

BIM - Building Information Modeling. AECO - Architecture, Engineering, Construction and Operation.

NIST - National Institute of Standards and Technology. PDCA - Plan, Do, Check and Act.

FM - Facility Management.

\section{Introduction}

One of the main problems faced by the manufacturing sector nowadays is managing several resources in an interdisciplinary and integrated way. Several studies in production planning and control have been carried out on Lean Thinking (Khadem et al. 2008; Romero, Martín 2011; Chong et al. 2013; Serrano 2016) in order to decrease waste and lead time, improve productivity and efficiency, and add value to operations. Construction has a dispersed management method. This sector has the necessity to adapt processes and procedures aiming a more integrated approach to harmonize technology and people toward strategic goals. According to Sacks et al. (2010),
Lean Thinking, as well as Building Information Modeling (BIM), has the potential to remarkably change Architecture, Engineering, Construction and Operation (AECO). Within the last twenty years, both methodologies became innate attributes of the project in engineering processes, aiming to improve documentation quality as well as predictability (Wang et al. 2013; Yang, Ergan 2016; Ivson et al. 2018).

Construction projects have a very iterative and changeable structure, leading to constant design changes. Their composition and formation are not constant or fixed; they are continuously changing. Modifications are not restricted to design phases, they can happen after the construction starts, especially regarding fast-track projects. Therefore, management changes are fundamental for efficient accomplishment of construction projects. Given that, BIM is a powerful tool to support an integrated lifecycle management, from the design phase to operation, based on a smoother coordination process (Pilehchian et al. 2015). BIM has impact on short term - driving productivity and quality toward higher levels - and encourage bigger

${ }^{*}$ Corresponding author. E-mail: daniel_nascimento@id.uff.br 
changes in processes related to management, as it provides tools to coordinate a substantial amount of information, a main principle of Lean Production (Womack, Jones 2003; Nascimento et al. 2018).

According to GCR NIST (2004) by the National Institute of Standards and Technology (NIST), an U.S. Department of Commerce laboratory, states that losses in the oil and gas industry are associated with failures in the integration of engineering tools. Problems related to interoperability in information flows and systems structures caused a US\$ 15.8 billion dollars a year debt. Dave et al. (2015) claims that to encourage unification among processes, technologies and people, synergies between Lean methodology and BIM are mandatory. Summarizing, Lean Thinking is a methodology that aims reductions towards enhancement: fewer equipment, space, staff and human efforts to achieve better results related to the real needs of the clients. As a result, more efficient processes leads to less waste, generating better customer values (Comm, Mathaisel 2006).

Lean Thinking and BIM, according to Sacks et al. (2010), are nonrelated initiatives and, in the current stage of both, probably, professional and companies are still in the beginning of the learning curve in each approach. Meanwhile, if their synergy is properly understood, both methodologies can be explored in favor of improving engineering and AEC processes. Otherwise, Arayici et al. (2011) states that implementation of BIM in companies still faces challenges. The main reasons to stall larger adoption is lack of orientation or practical studies to support users and drive improvements in knowledge regarding BIM. Consequently, it reduces improvements in productivity, efficiency and quality.

The three objectives of this article are: (1) define both concepts - BIM and Lean; (2) analyze interrelationships between them; and (3) apply an innovative model called the Digital Obeya Room (Nascimento et al. 2018) for facility management. The synergies of BIM and Lean methodology underpin the model aiming continuous improvement. An empirical study was conducted to evaluate the methodology in real-world maintenance planning of industrial plant facility. In addition, to analyze perceptions of professionals and academics, a survey was applied on non-probabilistic sample with representative Brazilian workers, specialists in BIM-Lean approaches. This paper demonstrates effectiveness in pursuance of linking the gap between engineering management, safety of information and communication employing Lean approach and BIM technologies together, with the goal of promoting an interdisciplinary knowledge of collaborative management.

\section{Research methodology}

This paper is based on an exploratory approach, aiming to bring up significant information of Building Information Modeling tools and Lean principles regarding implementation in construction projects, in order to identify the applicability level of visual management in PDCA cycle. In addition, it can be classified as descriptive due to the aim to disclose a manner to present information, showing its reflexes on related environments. To consolidate the methodology, a case study method using the Digital Obeya Room was completed, including its application in a real project and comparison and discussion of this analysis with the results of a survey applied to specialists in order to assess the relevance of each BIM-Lean principles for facility management. The research study applied a triangulated methodology with qualitative and quantitative data collection mechanisms. The data was gathered using three methodologies:

1) Literature review on the related works of BIM-Lean approaches, through an intuitive and inductive way;

2) Empirical investigation is carried out in an industrial plant facility to evaluate the BIM methodologies and technologies for the preventive maintenance planning and control; and

3) Application of a survey questionnaire with managers, researches and BIM specialists to assess the relevance of each of the BIM-Lean principles for the construction industry.

It may be observed that the research counts on multiple sources of information and iteration with the constructs developed from the literature, which enables further constructive validity (Eisenhardt 1989). To Miguel (2005), the use of multiple sources allow for the support of the constructs, propositions and hypotheses, in other words, the technical use of triangulation helps in the iteration and convergence between various sources of evidence. The empirical study was considered acceptable as the data are gathered from diverse procedures, avoiding the subjectivity of the researcher and guaranteeing the quality of the results (Yin 2005); and increasing the precision of empirical research (Runeson, Höst 2009).

\section{Literature background}

The bibliographic review conceptualizes the meaning and current scenario of Lean Thinking principles and BIM functionalities. In addition, we evaluate work related in the literature that identified synergies between BIM and Lean Thinking, seeking continuous and incremental improvement of engineering processes. The following section describes the concept and functionality of BIM.

\subsection{Principles of Building Information Modeling}

Eastman et al. (2008) is the main guide for BIM within the industry. According to the book, Building Information Modeling is not only a three-dimensional representation of a building but a denomination to a modern approach regarding building design and its management. The method encompass techniques, procedures and tools supported by a full digital, computer-readable documentation about a construction during every stage of its lifecycle: project, design, construction and operation. Summarizing, BIM does not describe the model itself, but a new methodology for develop and management of a building. 
The three-dimensional representation is referred as 'building information model', or solely 'model' as above.

Building Information Modeling is one of the most promising improvements related to automation and mechanization within the Architecture, Engineering and Construction industry. This technology enclose functions to ease a more cooperative design and concept of a building, detecting physical conflicts between objects and enabling a simultaneous authoring by numerous domain experts (Kreider et al. 2010). Therefore, the technology has the potential to be an improvement for project management concerning process and procedures. This development can be a solid underpin for application of Lean principles in a very effective approach (Bryde et al. 2013).

Arayici et al. (2011) stated that the adoption of BIM should follow a bottom-up approach instead of a topdown one. Most importantly, people shall be involved in every step of the implementation to ensure development of skills, acceptance of changes and, foremost, the understanding about the continuous improvement strategies. The author states that the implementation of BIM follow a seven-pillar strategy: to reduce waste to the minimum, if possible, none; to increase feedback; to evaluate decisions toward a full agreement; to fasten delivery; to build on integrity; to enhance knowledge of the team and have a broader perspective aiming the "big picture". Diversely, Eastman et al. (2008) and Sacks et al. (2010) recommend that for BIM to achieve its full potential, i.e. provide collection, alteration, evaluation and report of information related to building projects, some procedures have to be inherent. The BIM functionalities (see Figure 6) presented by Eastman et al. (2008) and Sacks et al. (2010) should be evaluated in relation to the engineering systems required to support technologies, and also to the BIM maturity level of skills (knowledge, skills and attitudes). These features require a Lean methodology for production management regarding sustainable development.

\subsection{BIM applications for facility management}

According to a study by the NIST, $85 \%$ of the lifecycle cost from facility occurs after commsioning (GCR NIST 2004). Operations and maintenance phases are responsible for $\$ 10$ billion in losses due to time-consuming information access and poor management practices. Despite this, BIM applications in facility management (FM) are still rare. A survey with professionals from different organizations found that only $42 \%$ of users employed it during operations and maintenance phases (Becerik-Gerber, Rice 2010; Becerik-Gerber et al. 2012). According to the study, FM applications best supported by 3D CAD include: locating building components, facilitating real-time data access, visualization and marketing, checking maintainability, and space management.

Research by Patacas et al. (2015) investigated how BIM data standards could deliver asset information required by facility managers within a whole life cycle perspective. Results indicated many data requirements which were not satisfied by current industry standards and suggested best practices for smoother transition between design/ construction phases and the facility management phase. Later work by Thabet and Lucas (2017) documented the real world challenges of adopting BIM for facility management. The pilot study highlighted the need for improvements in current management practices and traditional operational processes. Around the same time, PishdadBozorgi (2017) called attention to the inefficiencies in current BIM solutions to meet facility management needs and requirements.

More recent research by Jang and Lee (2018) explored the impact of three organizational factors in BIM-based team coordination: number of participants, their heterogeneity, and the highest decision-maker involved. The coordination time linearly increased as each factor increased. The findings stressed the significance of integration between BIM and Lean approaches, such as Obeya (big room), to expedite decision-making processes and eventually to reduce the coordination time. Meanwhile, Wetzel et al. (2018) investigated the potential benefits of BIM for safety during facility management. The study proposed a Safety for Facilities Maintenance Framework that improved team communication and provided faster access to safety-critical information to FM personnel.

\subsection{Principles of Lean Thinking}

The Japanese developed Lean principles after the World War II. Its main principles are Just-in-Time flow, i.e. condition production to demand; and Jidoka automation, i.e. a disengagement of man and machine allowing a single operator to conduct a group of machines (Aziz, Hafes 2013). According to Villarreal et al. (2012) the Lean Production (LP) is based on a philosophy of continuous improvement, where the search for the source and the reduction of waste is fundamental. The author defines seven forms of waste, activities that add cost but no value: production of goods not yet ordered; waiting; rectification of mistakes; excess processing; excess movement; excess transport; and excess stock.

Lean production was adapted to other industries. The principles of reducing waste and increase productivity and efficiency still the main goals of the methodology despite the industry (Aziz, Hafes 2013). The adaptation for the construction industry was done by Koskela (1992), introducing a new model of production management, wherein can be conceptualized in three complementary ways: (1) Transformation, (2) Flow, and (3) Value generation (TFV). As the author states, eleven principles can summarize Lean Thinking (LT). Later, Sacks et al. (2010) incremented four more principles. It is possible to perceive some synergies between BIM functionalities and Lean principles. Throughout the next section we evaluate related works that identified connections within the two methodologies.

\subsection{Synergies between BIM and Lean for facility management}

Summarizing, Lean construction can be classified as a methodology to enhance project management while BIM 
is an approach regarding information administration (Sacks et al. 2010). As mentioned above, BIM supports a more collaborative development and share of information among stakeholders. Therefore, Olatunji (2011) states that BIM can be associated with Lean approaches to a more efficient project management. Even though BIM and Lean Construction have not dependable or interconnected principles, some standards are affiliated beyond their contemporary approach (Sacks et al. 2010). Dave et al. (2015) described the synergic potential of the mentioned methodologies throughout the entire lifecycle of a construction project.

However, a simultaneous implementation on the current construction practices can strongly lead to misunderstandings and mistakes related to valuation of their contributions and improves on efficiency and productivity. The synergies were only analyzed during implementations of single designs lacking any systematic exploration strategy. In addition, there is no technology to integrate the principles and assure the synergies. Hosseini et al. (2018) states that to augment facility management (FM) performance towards business growth and prosperity it is crucial to convert a building in-use data and information into tangible business knowledge. However, as pointed by Carbonari et al. (2018), the uptake of BIM regarding FM still face several challenges such as lack of knowledge, compatibility among software, indefinition on ownership of data, information reliability and a missing technique to include existing building, which lead to the usage of BIM restricted to managers who work with new buildings.

In this context, Lean principles can be applied to the FM to identify the value and non-value added activities in the process (Sharma et al. 2007). Lean can improve the FM process by identifying actual value creation process between the input and output and providing tools for managing the value creation, but the leaner value creation practices need to be aligned with the new way of thinking in order to remove the waste activities of the facility management (Jylhä, Junnila 2013). Therefore, Lean principles and BIM functionalities can be combined to provide tools for managing the value creation challenges, supporting and improving the FM service process.

\section{The Digital Obeya Room}

Obeya is the word in Japanese for "large room". The first use related to management was by a Toyota executive aiming a better coordination of a complex engineering initiative. To ease understanding of other workers' opinions and facilitate its access, A3 sheets were hung up on the wall of a meeting room where each one had to write down a description of their point of view (Liker 2004; Morgan, Liker 2006).

As other Lean practices, the Obeya room have proved to be very successful in enhancing collaboration during management processes. It helps reach decisions in a more efficient and faster way (Shabazi, Javadi 2012), supports a meaningful reduce in waste (Terenghi et al. 2014), and help reduce organizational barriers (Oosterwal 2010). Participants can easily reach concerns and worries of other workers and reach a deeper awareness regarding problems. Therefore, a faster agreement is reached employing digital systems, a contemporary adaptation of the Obeya room was developed. Underpinned by the continuous improvement motto and based on the context of visual management, Digital Obeya Room targets to enhance efficiency and productivity regarding interdisciplinary project management (Terenghi et al. 2014). Diverse engineering systems were combined aiming a more unified access to information generated in several sources (as identified by the green boxes on Figure 1). The information is loaded to an integrated relational database and linked to

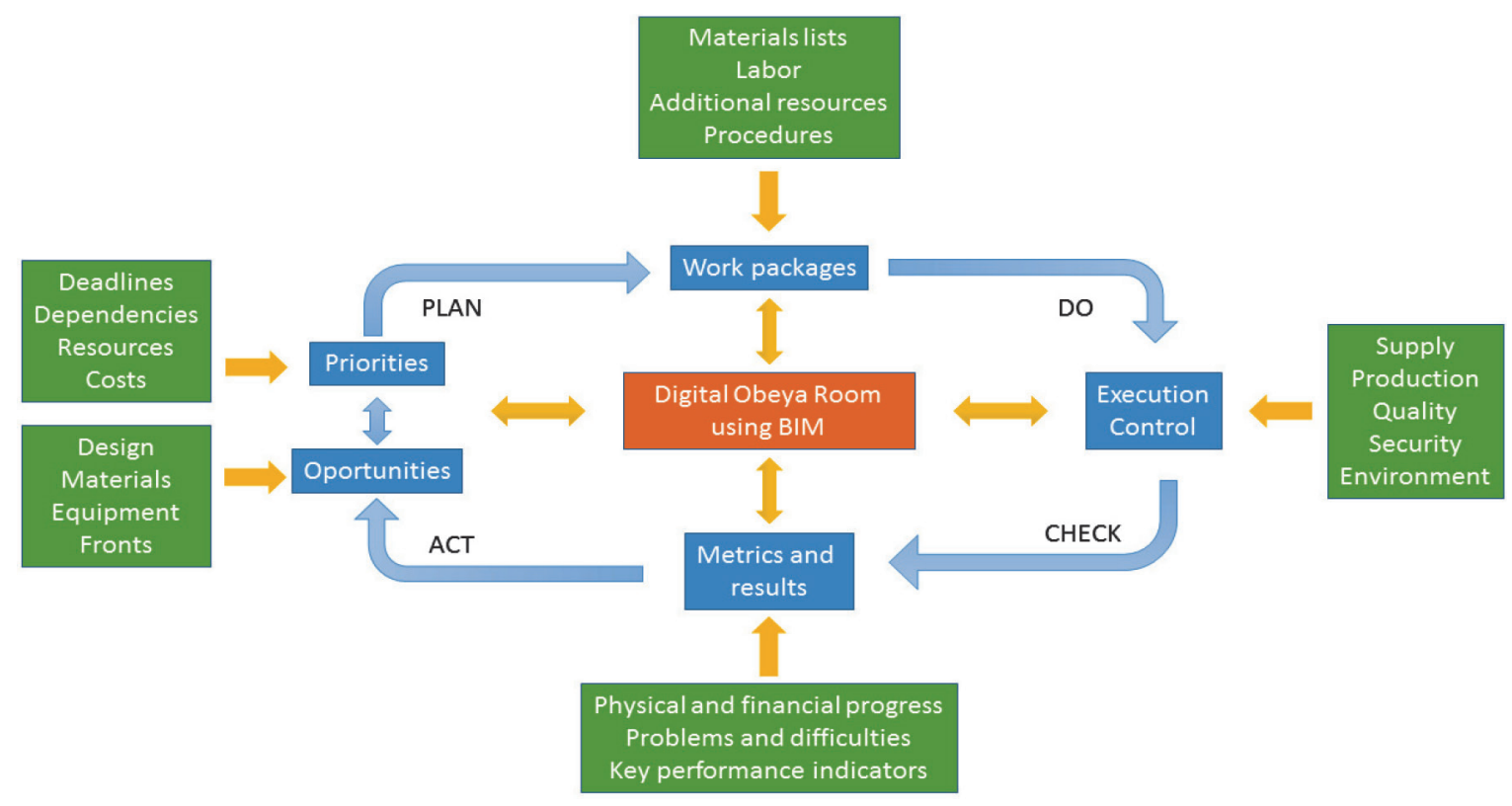

Figure 1. Framework for integration of Lean Thinking to BIM in the PDCA of the $\mathrm{nD}$ visual management 


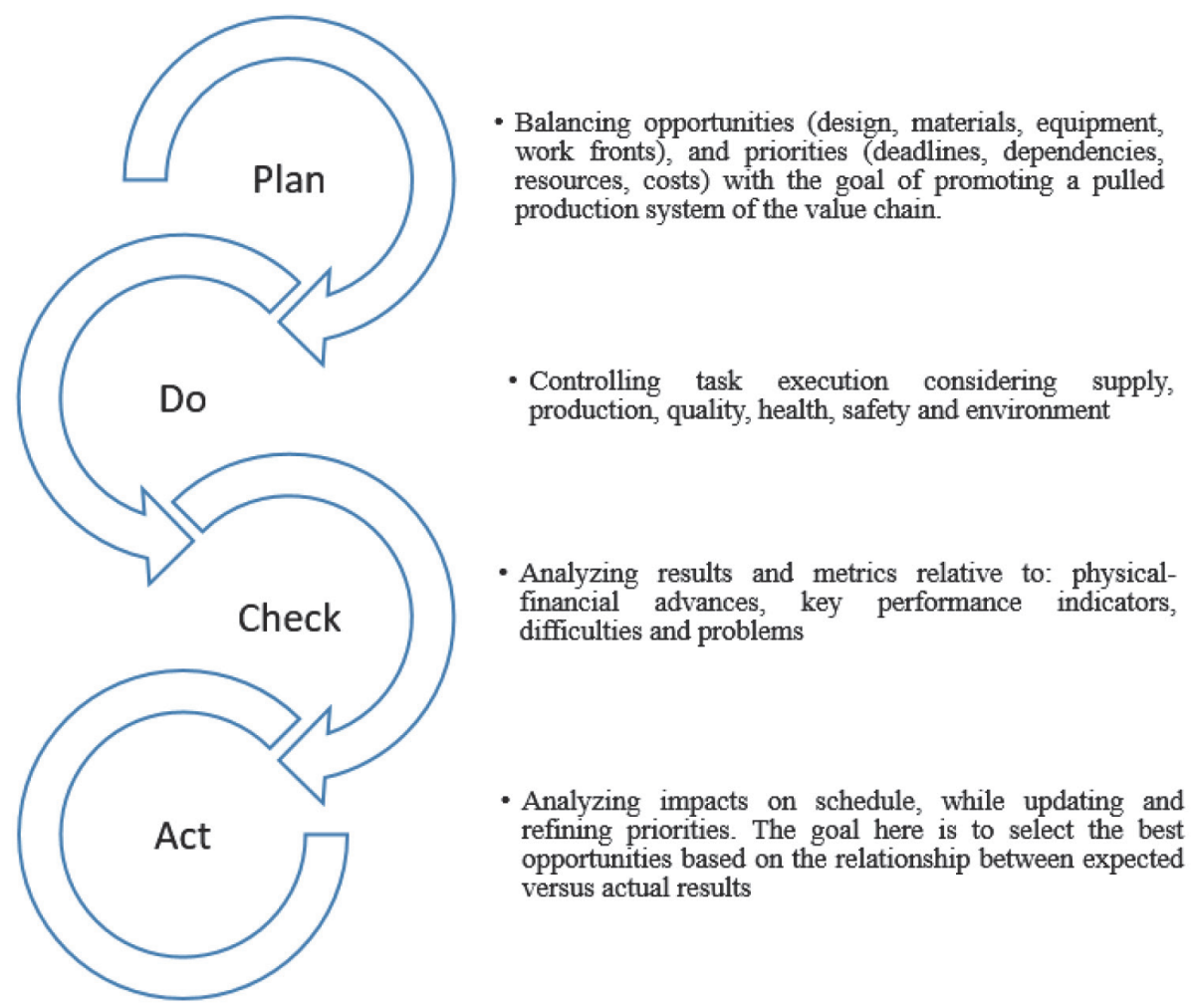

Figure 2. Standard operational procedure of Digital Obeya Room

multidimensional visualization within the PDCA methodology. The workflow (see Figure 2) aiming continuous improvement and validation of the procedures is described.

Three-dimensional visualization simulates work plans and contingencies in a visual and cooperative approach throughout every PDCA step. Actions regarding PDCA reports can be taken by stakeholders supported by $3 \mathrm{D}$ models. These models are an efficient approach to manage tasks on every continuous improvement step. Figure 3 illustrates decision processes that occur inside the Digital Obeya Room.

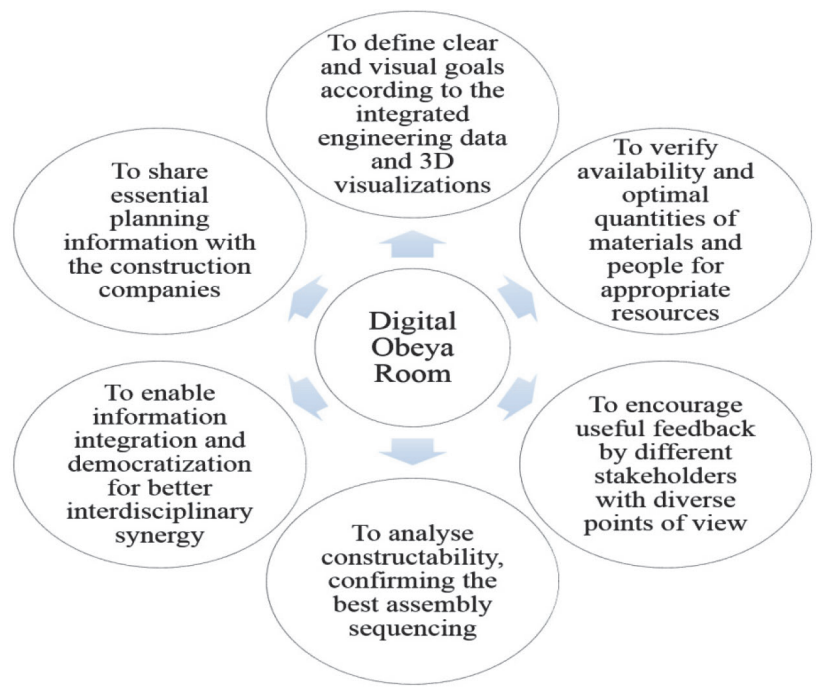

Figure 3. Guidelines in the Digital Obeya Room model
Summarizing, this framework gives the opportunity to control available resources by physical areas and to conduct work and material flows. Constructability analysis are enhanced by the visualization system and, therefore, can determine and validate work packages. Consequently, supply management are better guided in verification of storage availability and logistics, minimizing unnecessary material movements and aiming a FIFO (first-in, first-out) approach. Related to this context, Lean mizusumashi technique can be applied to stablish better routines for material management so that workforce can focus on assembly tasks.

\section{Empirical study}

The goal of this investigation was to improve maintenance processes in a scheduled stop, in a shale process plant. By applying the proposed methodology, it was possible to increase the effectiveness in communication among the project participant teams. The Digital Obeya Room provided a general overview of scheduled tasks, and contributed to reducing risks and increasing cooperation between teams. The consequences included less rework and decreased lead-time to perform tasks. Initially, data were collected from all items that required repair or replacement. This set of information was performed with the aid of the $\mathrm{nD}$ visualization system using computers at the shop floor. This provided an easy and practical interface to insert pending items and to have a visual control task executed through color-coding. An example of visualization is demonstrat- 


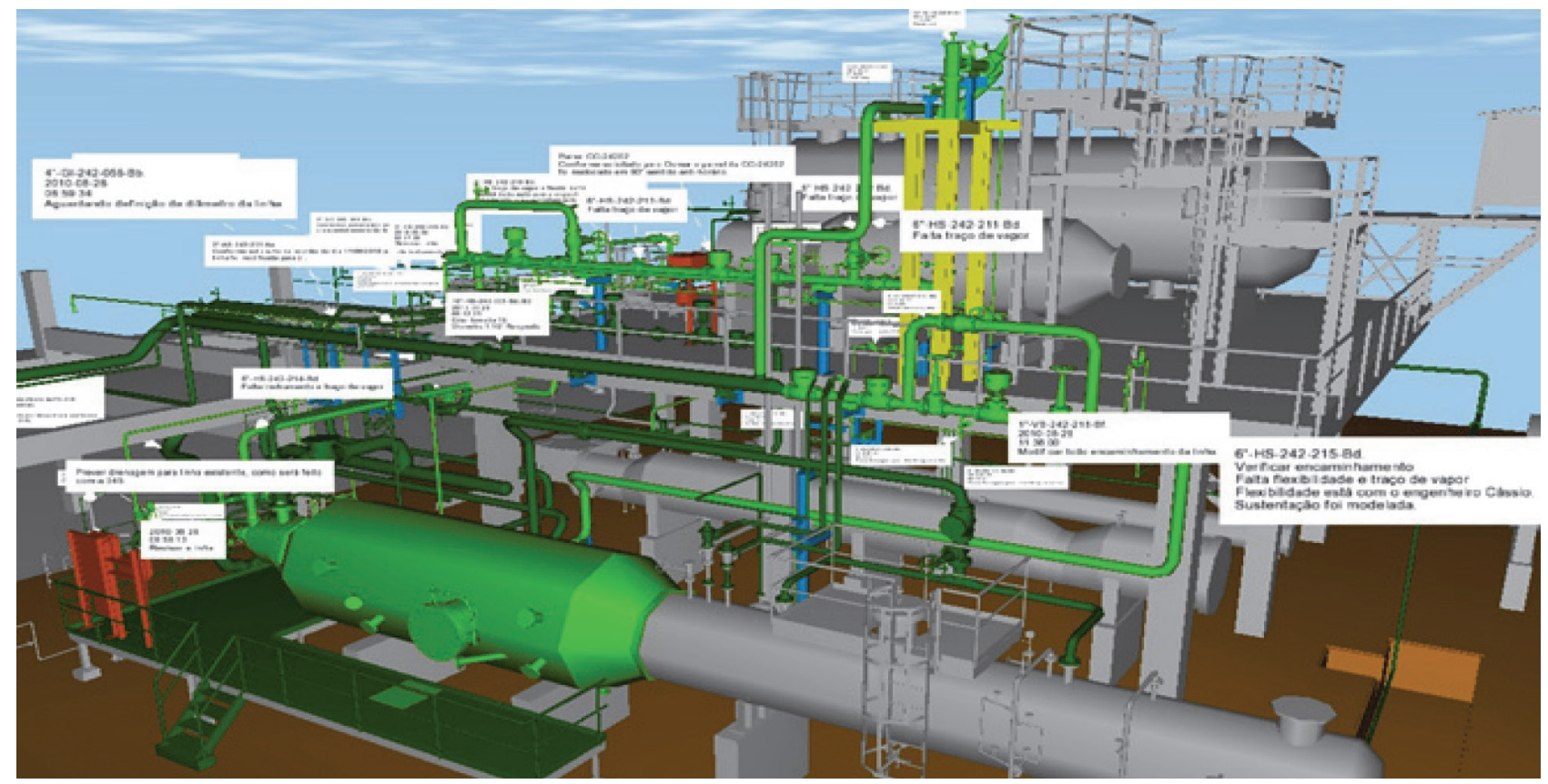

Figure 4. Collaboration between project and construction with $\mathrm{nD}$ viewer

ed in Figure 4, where the precise location of maintenance tasks can be identified in the 3D environment.

In this study, 16 meetings were held, containing 2 planning engineers, 1 operation supervisor, 2 maintenance engineers, and 1 Kaizen coordinator (leader of the production planning and control) for the sake of mapping pendencies, planning activities, and monitoring the maintenance stop of an industrial plant to refine the oil from the shale. The meetings happened inside the company, and the first 10 meetings were held in the morning of July 2016, according to the participants' availability, prior to the maintenance stop. After mapping the pendencies, determining the scope, and establishing the visual management in the Obeya Room, there were 4 sessions every Friday at 15 pm to evaluate the weekly productivity and to plan the maintenance activities of next week with the utilization of the 3D model. At the end of the project was conducted a brainstorm meeting, called lessons learned on management of knowledge workshop, to evaluate the BIM-Lean approaches on the maintenance management and determine the ones that were most beneficial during the process.

The increased communication and collaboration between expert teams improved the effectiveness of item procurement and just-in-time delivery of goods. These activities followed the concept of mizusumashi, to mobilize teams to execute the maintenance tasks. These benefits were also established in related works (Eastman et al. 2008; Sacks et al. 2010; Nascimento et al. 2017, 2018; Caiado et al. 2018). Moreover, in this empirical study can be noticed the application of some BIM-Lean approaches, as B6, B1, L8, and L15. At this point, it was possible to realize that the use of collaborative visual management generated greater synergy among employees to identify disputes or problems in the operation of the plant. These problems have been stored and updated on the corporate network; creating ease of information to plan future preventive maintenance shutdowns. With the definition of the work packages within a more appropriate sequencing of maintenance, it was possible to carry out this task with greater assertiveness between what was planned and done.

\section{Survey with industry professionals}

Next, a survey was fullfill to measure the implications of BIM-Lean approaches, according to the perception of professionals that working in the oil and gas sector. Survey design was informed by discussion with a research specialist and a preliminary review of the literature. A pilot survey questionnaire was answered by four professionals, two collaborators who were knowledge on BIM concepts, including a manager involved in the case study and an engineer from a construction company. Thus, the revised questionnaire offers a better refinement of the questions, ensuring that experts, professionals and academics would have no difficulty in answering the questions. In order to organize the questionnaire in a logical sequence and to better understand the subject studied, the questionnaire is divided into two areas. The first area determines the demographic details of the specialists, such as gender, age, education degree and years of experience with BIM. The second area focussed on analyze the degree of relevance of each BIM-Lean principle. All responses on the relevance of guidelines items were recorded using a five point Likert scale (1 - "very applicable" to 5 - "very applicable").

An electronic questionnaire is developed for data collection in "Google forms" (https://docs.google.com/ forms). The length of time to answer the questionnaire was about 15 minutes. In November 2016, the web-based 
surveys were distributed via email to twenty managers currently active in the construction industry, eighteen researchers and twenty-six BIM operators/experts. Therefore, the intended population of this study consists of 64 professionals who are users of BIM technologies and practitioners of Lean techniquesSampling for convenience is done (Sekaran, Bougie 2010), since this study aims to investigate the most applicable variables (Calder et al. 1981). The period of application of the research was approximately five months, ending in March, 2017.

A total of 41 questionnaires were collected and after the manual screened check of the data, ignoring those with incomplete questions, this resulted in 32 valid questionnaires. According to Hines and Montgomery (1990) and Sureeyatanapas et al. (2015) in small populations, a questionnaire with a sample of at least 30 respondents allows a acceptable descriptive statistic. Descriptive statistics were used, including frequencies, percentages and mode, to describe sample characteristics analyzed. Table 1 details the respondents' profile.

The professionals interviewed are predominantly managers, accounting for $41 \%$ of the total. Following by $38 \%$ of BIM operators/experts. The majority of interviewees are between 18 and 30 years old (50\%), and $40 \%$ of respondents have more than ten years of experience. In addition, around $50 \%$ of interviewees have at least a master's degree, which shows a high level of maturity and academic formation. Thus, the sample was considered adequate for the research. Then, from the empirical study carried out, the principles of BIM and Lean were rated in agreement with the perceptions of the specialists of the survey. We used descriptive statistics, including frequencies and percentages, to present the results. As shown in Figures 5 and 6 ,
Table 1. Characteristics of study respondents

\begin{tabular}{|c|c|c|}
\hline & Number & Percentage \\
\hline \multicolumn{3}{|l|}{ Sex } \\
\hline Male & 24 & $75 \%$ \\
\hline Female & 8 & $25 \%$ \\
\hline \multicolumn{3}{|l|}{ Age group } \\
\hline $18-30$ & 16 & $50 \%$ \\
\hline $31-50$ & 12 & $37 \%$ \\
\hline$>50$ & 4 & $13 \%$ \\
\hline \multicolumn{3}{|l|}{ Education degree } \\
\hline Undergraduate & 3 & $9 \%$ \\
\hline Graduate & 7 & $22 \%$ \\
\hline Postgraduate & 6 & $19 \%$ \\
\hline Master & 9 & $28 \%$ \\
\hline Doctor & 7 & $22 \%$ \\
\hline \multicolumn{3}{|l|}{ Years of experience } \\
\hline None & 4 & $12 \%$ \\
\hline Less than a year & 3 & $8 \%$ \\
\hline One to three years & 4 & $12 \%$ \\
\hline Four to six years & 6 & $20 \%$ \\
\hline Seven to ten years & 3 & $8 \%$ \\
\hline More than ten years & 13 & $40 \%$ \\
\hline \multicolumn{3}{|l|}{ Job/Function } \\
\hline Manager & 13 & $41 \%$ \\
\hline Researcher & 7 & $22 \%$ \\
\hline BIM operator/expert & 12 & $38 \%$ \\
\hline
\end{tabular}

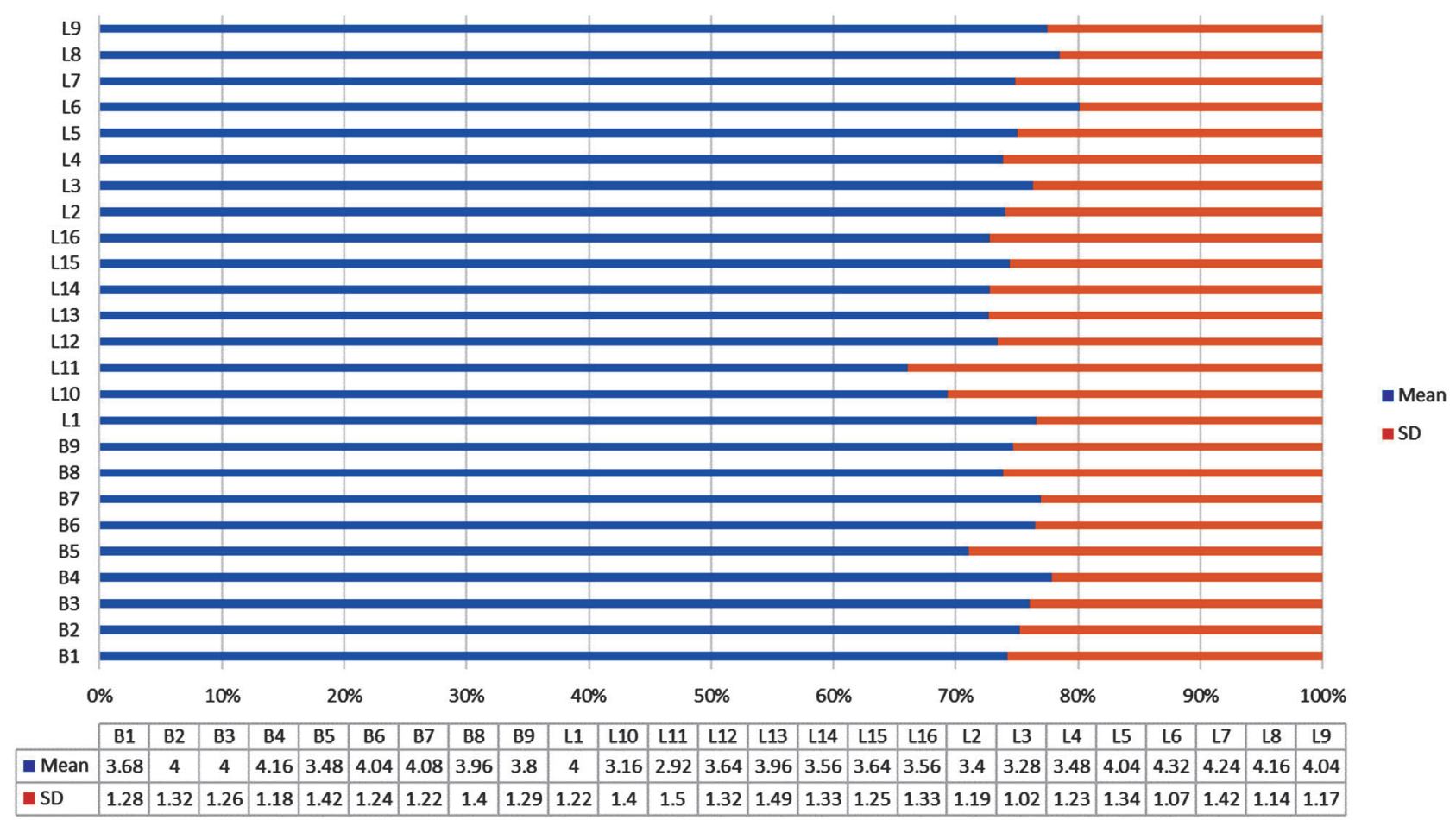

Figure 5. Descriptive results of most relevant BIM functionalities and Lean principles 


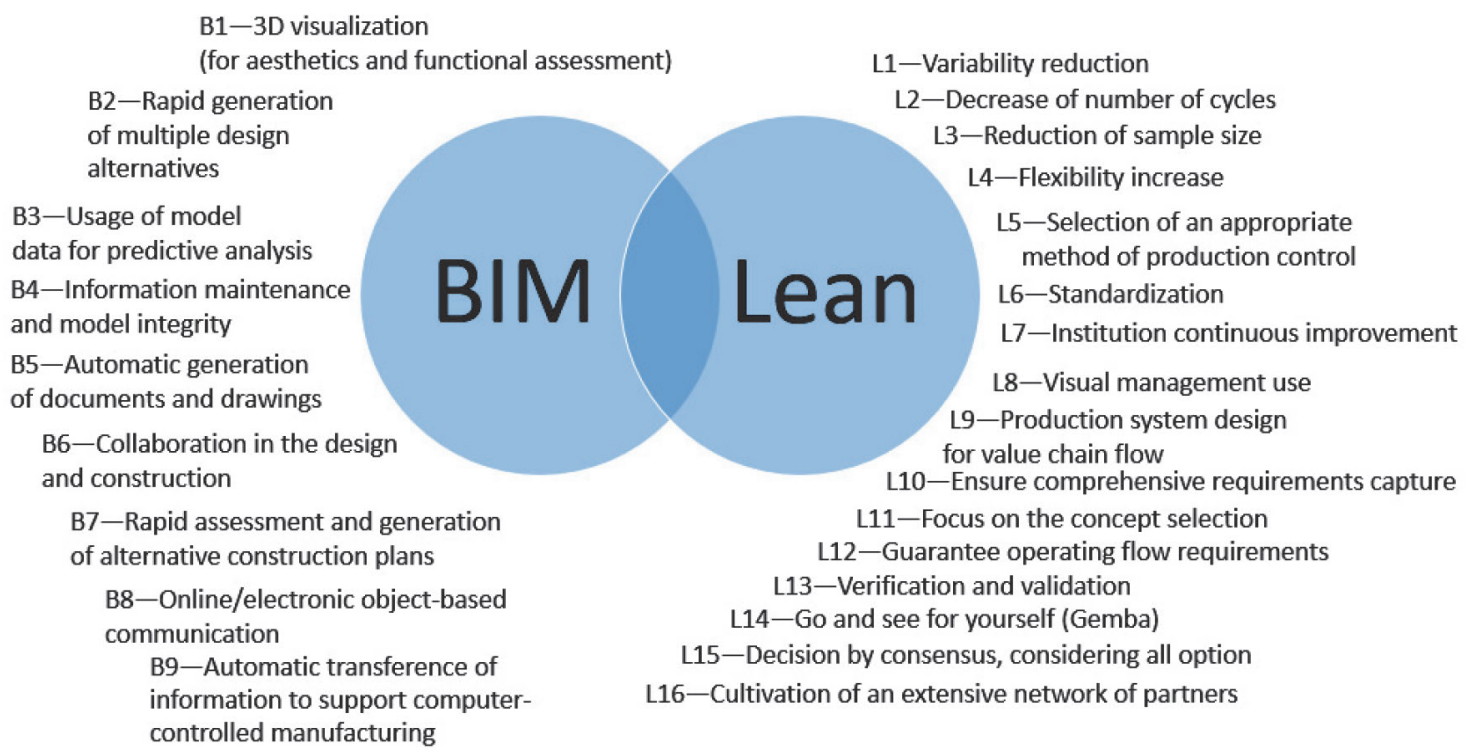

Figure 6. BIM functionalities and Lean principles. Source: adapted from Sacks et al. (2010)

BIM functionalities and Lean principles were ordered according to a measurement of position, the median. Hence, there is comparison between empirical analysis and the survey results in order to verify which BIM-Lean principle is more relevant for construction projects.

Figures 5 and 6 demonstrate the results from questionnaire. This figure indicates which principles of Lean principles (L1 to L16) and BIM functionalities (B1 to B9) are the most relevant to be used in the proposed framework to achieving Kaizen. The professionals perceived the practice of visual management as a significant contributor to lowering the barriers of time, cost, quality, scope, and safety. Besides that, the Figure 5 indicates that principles and functionalities as L6, L7, L8, B4, B7, L5, L9 and B6, have stood out as fundamental to achieving continuous and incremental improvement of engineering processes in the expert's view. Above all, in order to evaluate the vari- ables that influence the attitude of the people to the Digital Obeya Room, the importance attributed to each of them is presented in Figure 7.

It is noted that affective commitment to change and management support have stood out, however, routine work area and kaizen's experience have shown themselves to be indifferent as influencers in people's attitude. In addition, the ability of a Kaizen team should be evaluated. As the purpose of the Digital Obeya Room is to establish a continuous and incremental improvement process, the variables that influence its capacity are evaluated in Figure 8.

It can be noticed that team autonomy and team leader experience stood out as influencers for the increase of the Kaizen capacity of a team. However, routine work area, functional heterogeneity of the team and difficult of achieving goals were highlighted as less influential. It is

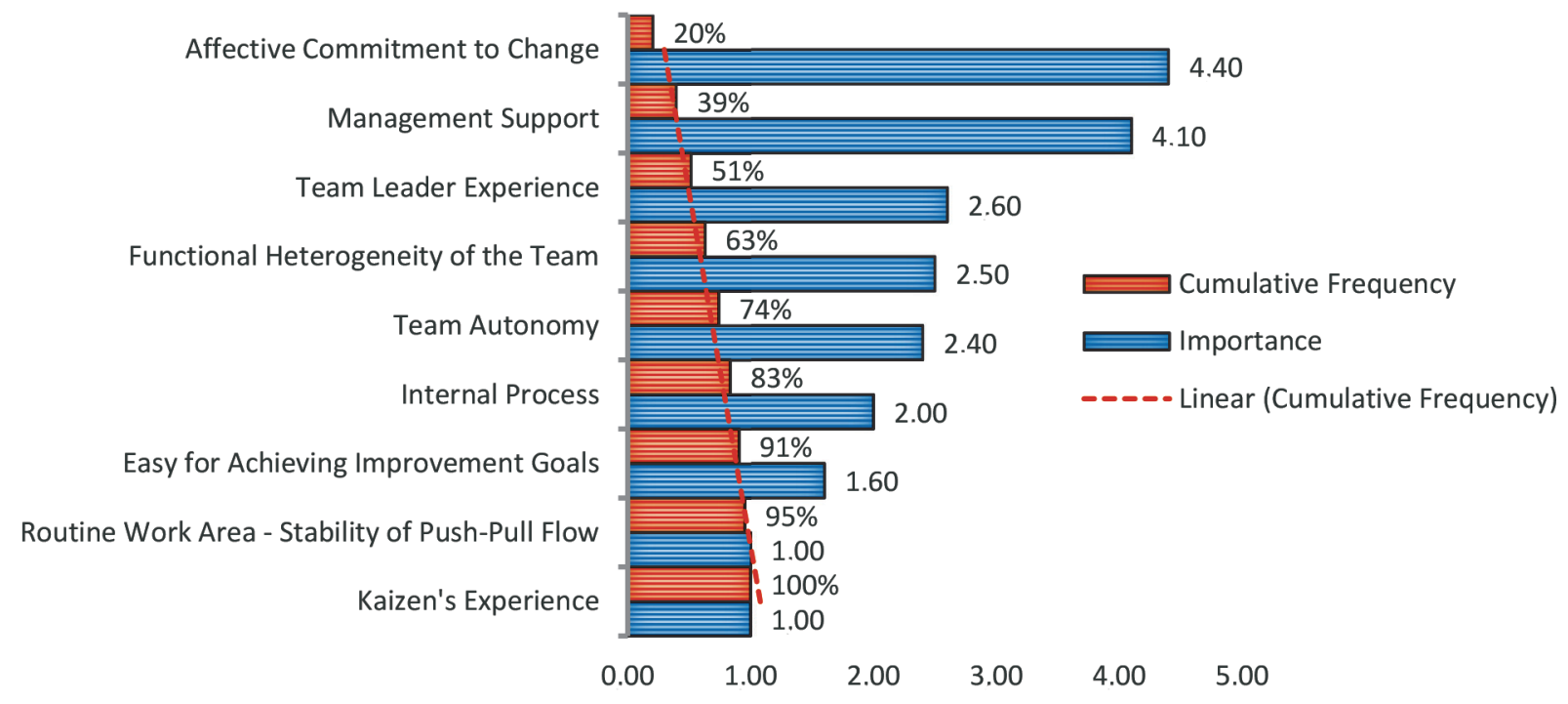

Figure 7. Most relevant attitudes of peoples to achieve Kaizen 


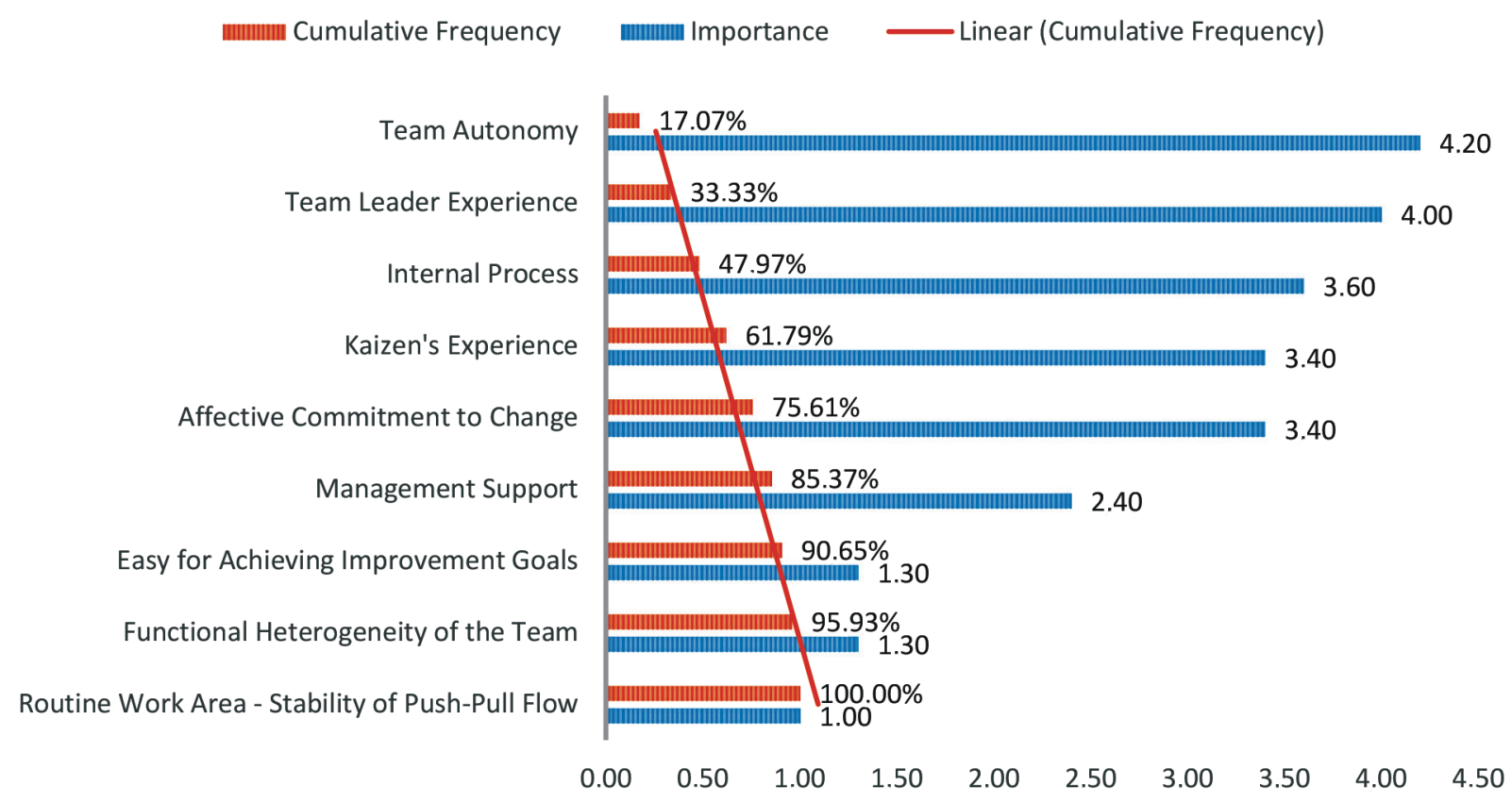

Figure 8. Most relevant capacity of team to achieve Kaizen

worth noting that for the implementation of the proposed model, the variables presented in Figures 6 and 7 should be monitored.

\section{Conclusions and future work}

This study helps both academics and practitioners decide which management strategy better suit their needs, guiding theirs actions related to prioritizing principles and describe synergies between Lean and BIM in order to enhance scheduling procedures, reduce waste, improve quality, define a precise scope for a project, avoid errors, motivate participants and promote a management effort that is supported by clear communication and shared information in the construction sector. The results of the analysis proved to be fundamental for the management and decision-making regarding the planning and control of maintenance in construction projects. With regards to the empirical study, the applied lean principles and BIM functionalities B6, B1, L8 and L15. On the other hand, the survey indicated that the four most relevant principles were L6, L7, L8 and B4. Therefore, despite these principles were perceived as main points for the continuous improvement of construction projects, the visual management was pointed out as the key principle for the proposed model because the multidimensional data visualization was the common environment for the interdisciplinary management through the PDCA cycle.

Also, our findings provide a better picture to understand the critical lean and BIM principles and these analyses serves the benchmarking for future operations and strategies of construction projects. This paper contributes from a practical approach to the performability around maintenence planning, making the schedule more adherent to actual achievement timetables and improving col- laboration among stakeholders. Encouraging the use of Lean and BIM principles, it was possible to level resources better based on a pull production system and reduce rework and waste throughout construction.

From an academic perspective, this paper has seeks counter-measures to eliminate the gap in the literature by employing simultaneously lean principles and BIM functionalities for promote an interdisciplinary knowledge of collaborative management, and the conceptual model proposed contributes to the literature, since it can guide academics and researchers demonstrating ways in which they can use the proposed framework with the help of BIM models for an effective project control and continuous and incremental improvement of engineering processes. As a sequence to this work, aside from the possibility of counting on a survey with a larger sample composed by more experts and applying the Digital Obeya Room model in other circumstances, we suggest the attribution of different relevance to professional according to degree of experience of current job position to obtain a more accurate perception analysis.

\section{Acknowledgements}

The authors wish to thank Petrobras for their valuable partnership with Tecgraf Institute/PUC-Rio. We also thank the reviewers for their helpful comments and suggestions.

\section{Author Contributions}

D. L. M. Nascimento and O. L. G. Quelhas conceived the study and were responsible for the design, methodology, empirical evaluation and discussions. R. G. G. Caiado and M. J. Meiriño were responsible for data collection and data 
analysis of the survey. P. Ivson and S. D. J. Barbosa were in charge of the development of technology architecture and software.

\section{Funding}

The research was supported by the Brazilian Federal Agency for Support and Assessment of Post-Graduate Education (CAPES) - Universal Call 01-2016, Process Number: 430119/2016-0; and FOPESQ Call 2017 Proppi UFF.

\section{Disclosure Statement}

The authors do not have any competing financial, professional, or personal interests from other parties.

\section{References}

Arayici, Y.; Coates, P.; Koskela, L.; Kagioglou, M.; Usher, C.; O'Reilly, K. 2011. Technology adoption in the BIM implementation for lean architectural practice, Automation in Construction 20(2): 189-95.

https://doi.org/10.1016/j.autcon.2010.09.016

Aziz, R. F.; Hafez, S. M. 2013. Applying lean thinking in construction and performance improvement, Alexandria Engineering Journal 52(4): 679-695.

https://doi.org/10.1016/j.aej.2013.04.008

Becerik-Gerber, B.; Jazizadeh, F.; Li, N.; Calis, G. 2012. Application areas and data requirements for BIM-enabled facilities management, Journal of Construction Engineering and Management 138(3): 431-442.

https://doi.org/10.1061/(ASCE)CO.1943-7862.0000433

Becerik-Gerber, B.; Rice, S. 2010. The perceived value of building information modeling in the U.S. building industry, Journal of Information Technology in Construction 15: 185-201.

Bryde, D.; Broquetas, M.; Volm, J. M. 2013. The project benefits of Building Information Modelling (BIM), International Journal of Project Management 31(7): 971-980. https://doi.org/10.1016/j.ijproman.2012.12.001

Caiado, R. G. G.; Quelhas, O. L. G.; Nascimento, D. L. M.; Anholon, R.; Leal Filho, W. 2018. Measurement of sustainability performance in Brazilian organizations, International Journal of Sustainable Development \& World Ecology 25(4): 312-326. https://doi.org/10.1080/13504509.2017.1406875.

Calder, B. J.; Lynn, W. P.; Tybout, A. M. 1981. Designing research for application, Journal of Consumer Research 8: 197-207. https://doi.org/10.1086/208856

Carbonari, G.; Stravoravdis, S.; Gausden, C. 2018. Improving FM task efficiency through BIM: a proposal for BIM implementation, Journal of Corporate Real Estate 20(1): 4-15.

Chong, M. Y.; Chin, J. F.; Loh, W. P. 2013. Lean incipience spiral model for small and medium enterprises, Journal of Industrial Engineering: Theory, Applications and Practice 20(7-8).

Comm, C. L.; Mathaisel, D. F. X. 2005. A case study in applying lean sustainability concepts to universities, International Journal of Sustainability in Higher Education 6(2): 134-146. https://doi.org/10.1108/14676370510589855

Dave, B.; Kubler, S.; Pikas, E.; Holmström, J.; Singh, V.; Främling, K.; Koskela, L.; Peltokorpi, A. 2015. Intelligent products: shifting the production control logic in construction (with Lean and BIM), in Proceedings of the $23^{\text {rd }}$ Annual Conference of the International Group for Lean Construction, 2015, Perth, Australia, 341-350.
Eastman, C. M.; Teicholz, P.; Sacks, R.; Liston, K. 2008. BIM handbook: A guide to building information modeling for owners, managers, architects, engineers, contractors, and fabricators. Hoboken, N.J.: Wiley. https://doi.org/10.1002/9780470261309

Eisenhardt, K. M. 1989. Building theories from case study research, Academy of Management Review 14(4): 532-550. https://doi.org/10.5465/amr.1989.4308385

GCR NIST. 2004. Cost analysis of inadequate interoperability in the US capital facilities industry. National Institute of Standards and Technology (NIST).

Hines, W. W.; Montgomery, D. C. 1990. Probability and statistics in engineering and management science. $3^{\text {rd }}$ ed. New York: Wiley.

Hosseini, M. R.; Roelvink, R.; Papadonikolaki, E.; Edwards, D. J.; Pärn, E. 2018. Integrating BIM into facility management: Typology matrix of information handover requirements, International Journal of Building Pathology and Adaptation 36(1): 2-14. https://doi.org/10.1108/IJBPA-08-2017-0034

Ivson, P.; Nascimento, D.; Celes, W.; Barbosa, S. D. 2018. CasCADe: A novel 4D visualization system for virtual construction planning, IEEE Transactions on Visualization and Computer Graphics 24(1): 687-697.

https://doi.org/10.1109/TVCG.2017.2745105

Jang, S.; Lee, G. 2018. Impact of organizational factors on delays in BIM-based coordination from a decision-making view: A case study, Journal of Civil Engineering and Management 24(1): 19-30.

Jylhä, T.; Junnila, S. 2013. Learning from lean management going beyond input-output thinking, Facilities 31(11/12): 454-467. https://doi.org/10.1108/F-11-2011-0097

Khadem, M.; Ali, S. A.; Seifoddini, H. 2008. Efficacy of Lean metrics in evaluating the performance of manufacturing systems, International Journal of Industrial Engineering: Theory, Applications and Practice 15(2): 176-184.

Koskela, L. 1992. Application of the new production philosophy to construction. Technical Report No. 72. Center for Integrated Facility Engineering (CIFE), Stanford University, CA.

Kreider, R.; Messner, J.; Dubler, C. 2010. Determining the frequency and impact of applying BIM for different purposes on projects, in Proceedings of the $6^{\text {th }}$ International Conference on Innovation in Architecture, Engineering and Construction (AEC), 2010, Loughborough, UK.

Liker, J. K. 2004. The Toyota way: 14 management principles from the world's greatest manufacturer. New York: McGraw-Hill.

Miguel, P. A. C. 2005. Recomendações na Adoção de Estudo de Caso como Abordagem Metodológica. XII SIMPEP - Bauru, SP, Brasil.

Morgan, J. M.; Liker, J. K. 2006. The Toyota product development system. New York: Productivity Press.

https://doi.org/10.4324/9781482293746

Nascimento, D. L. D. M.; Sotelino, E. D.; Lara, T. P. S.; Caiado, R. G. G.; Ivson, P. 2017. Constructability in industrial plants construction: A BIM-lean approach using the digital Obeya Room framework, Journal of Civil Engineering and Management 23(8): 1100-1108.

https://doi.org/10.3846/13923730.2017.1385521

Nascimento, D.; Caiado, R.; Tortorella, G.; Ivson, P.; Meiriño, M. 2018. Digital Obeya Room: exploring the synergies between BIM and lean for visual construction management, Innovative Infrastructure Solutions 3: 19.

https://doi.org/10.1007/s41062-017-0125-0

Olatunji, O. A. 2011. Modelling the costs of corporate implementation of building information modelling, Journal of Financial Management of Property and Construction 16(3): 211-231. https://doi.org/10.1108/13664381111179206 
Oosterwal, D. P. 2010. The Lean machine. USA: AMACOM.

Patacas, J.; Dawood, N.; Vukovic, V.; Kassem, M. 2015. BIM for facilities management: Evaluating BIM standards in asset register creation and service life planning, Journal of Information Technology in Construction 20: 313-331.

Pilehchian, B.; Staub-French, S.; Nepal, M. P. 2015. A conceptual approach to track design changes within a multi-disciplinary building information modeling environment, Canadian Journal of Civil Engineering 42(2): 139-152. https://doi.org/10.1139/cjce-2014-0078

Pishdad-Bozorgi, P. 2017. Future smart facilities: State-of-theart BIM-enabled facility management, Journal of Construction Engineering and Management 143(9). https://doi.org/10.1061/(ASCE)CO.1943-7862.0001376

Romero, B. P.; Martín, M. G. 2011. Implementing Lean manufacturing by means of action research methodology. Case study in the aeronautics industry, International Journal of Industrial Engineering: Theory, Applications and Practice 18(12): 611-619.

Runeson, P.; Höst, M. 2009. Guidelines for conducting and reporting case study research in software engineering, Empirical Software Engineering 14(2): 131-164. https://doi.org/10.1007/s10664-008-9102-8

Sacks, R.; Radosavljevic, M.; Barak, R. 2010. Requirements for building information modeling based lean production management systems for construction, Automation in Construction 19(5): 641-655. https://doi.org/10.1016/j.autcon.2010.02.010

Sekaran, U.; Bougie, R. 2010. Research methods for business: A skill building approach. London: Wiley.

Serrano, I. 2016. Takt time as a lever to introduce lean production in mixed engineer-to-order/make-to-order machine tool manufacturing companies, International Journal of Industrial Engineering: Theory, Applications and Practice 23(2): 94-107.

Shabazi, S.; Javadi, S. 2012. Supporting production system development through Obeya concept: Master thesis. School of Innovation, Design and Engineering, Mälardalen University, Sweden.

Sharma, V.; Abel, J.; Al-Hussein, M.; Lennerts, K.; Pfründer, U. 2007. Simulation application for resource allocation in facility management processes in hospitals, Facilities 25(13/14): 493-506. https://doi.org/10.1108/02632770710822599

Sureeyatanapas, P.; Yang, J. B.; Bamford, D. 2015. The sweet spot in sustainability: a framework for corporate assessment in sugar manufacturing, Production Planning \& Control 26(13): 1128-1144. https://doi.org/10.1080/09537287.2015.1015470

Terenghi, F.; Cassina, J.; Kristensen, K.; Terzi, S. 2014. Virtual Obeya: A new collaborative web application for running lean management workshops, in International Conference on Engineering, Technology and Innovation: Engineering Responsible Innovation in Products and Services (ICE 2014), 2014, IEEE. https://doi.org/10.1109/ICE.2014.6871554

Thabet, W.; Lucas, J. 2017. Asset data handover for a large educational institution: Case-study approach, Journal of Construction Engineering and Management 143(11). https://doi.org/10.1061/(ASCE)CO.1943-7862.0001389

Villarreal, B.; Garza, F.; Rosas, I.; Garcia, D. 2012. An introduction to distribution operational efficiency, International Journal of Industrial Engineering 19(7): 278-288.

Wang, X.; Love, P. E. D.; Jeong, M.; Park, C.; Sing, C.; Hou, L. 2013. A conceptual framework for integrating building information modeling with augmented reality, Automation in Construction 34: 37-44.

https://doi.org/10.1016/j.autcon.2012.10.012
Wetzel, E. M.; Thabet, W. Y.; Jamerson, W. E. 2018. A case study towards transferring relevant safety information for facilities maintenance using BIM, Journal of Information Technology in Construction 23: 53-74.

Womack, J. P.; Jones, D. T. 2003. Lean thinking: Banish waste and create wealth in your corporation. New York: Simon \& Schuster.

Yang, X.; Ergan, S. 2016. Design and evaluation of an integrated visualization platform to support corrective maintenance of HVAC problem-related work orders, Journal of Computing in Civil Engineering 30(3).

https://doi.org/10.1061/(ASCE)CP.1943-5487.0000510

Yin, R. K. 2005. Estudo de caso: planejamento e métodos. $3^{\text {rd }}$ ed. Porto Alegre: Bookman. 